\title{
Suscetibilidade morfométrica de bacias de drenagem ao desenvolvimento de inundações em áreas costeiras
}

\author{
Celia Regina de Gouveia Souza \\ Instituto Geológico-SMA/SP \\ Av. Miguel Stéfano, 3900. 04301-903. São Paulo (SP). Tel.: (11) 50772160. \\ E-mail: celia@igeologico.sp.gov.br
}

\begin{abstract}
Resumo
Os fatores condicionantes de inundações e enchentes em regiões costeiras são de origem natural e/ou antrópica. Os condicionantes naturais são divididos em: climático-meteorológicos, geológico-geomorfológicos, flúvio-hidrológicos e oceanográficos. Os condicionantes antrópicos resultam de intervenções humanas diretas ou indiretas nas bacias de drenagem, podendo ser genericamente agrupados em: uso e ocupação de áreas marginais aos canais de drenagem (águas doces e mixohalinas); modificações na rede de drenagem e alterações nos processos sedimentares naturais e no balanço sedimentar do sistema costeiro. Inúmeros autores apontaram os parâmetros morfométricos da bacia de drenagem como fortemente correlacionados às características hidrológicas da mesma e, portanto, à sua suscetibilidade em desenvolver inundações. Essas correlações são feitas, em geral, isoladamente para cada parâmetro, ou para grupos pequenos de, no máximo, três ou quatro parâmetros. Isso ocorre porque há dificuldades em se estabelecer intervalos genéricos de referência para interpretações e classificações de graus de suscetibilidade dessas bacias ao desenvolvimento de inundações. O nível de complexidade aumenta quando várias bacias são analisadas em conjunto, sendo extremamente difícil comparar e interpretar os valores absolutos desses parâmetros entre si. Este trabalho apresenta um método de correlação de um conjunto de dezoito parâmetros morfométricos de bacias de drenagem do Litoral Norte de São Paulo, baseado no estabelecimento da "suscetibilidade morfométrica" dessas bacias ao desenvolvimento de inundações. A suscetibilidade morfométrica constitui um importante indicador na análise de riscos a inundações/enchentes. O método é simples e econômico, podendo ser utilizado para quaisquer números de parâmetros morfométricos e de bacias de drenagem. Ele permite a identificação de bacias homogêneas sob o ponto de vista morfométrico e, consequentemente, hidrológico. Portanto, a suscetibilidade morfométrica poderia também ser utilizada em métodos de identificação de bacias hidrologicamente homogêneas e regionalização de cheias, utilizado por hidrólogos especialmente para bacias onde não estão disponíveis dados hidrológicos.
\end{abstract}

Palavras-Chave: Drenagem costeira, inundação, suscetibilidade morfométrica.

\begin{abstract}
In costal regions, floods are controlled by several natural and/or anthropogenic factors. Natural factors are due to climate and hydrometeorological conditions, drainage basin geological-geomorphological characteristics, and hydrological and oceanographic processes. Anthropogenic factors are those induced by direct and/or indirect human interventions, such as: occupation of flood-prone areas, and changes in drainage network and on sedimentary processes modifying the sedimentary budget of the coastal system. Many authors have demonstrated that drainage basin morphometry is an important control on unit hydrographic parameters and, therefore, on the resulting hydrograph shape of flooding events. In other words, morphometric parameters are correlated to the drainage basin susceptibility to floods. Due to the fact that it is impossible to establish generic trends between the absolute values of these parameters, in general, the interrelationships between them are made based on either a small group (less than four) of morphometric parameters or each one lonely. Besides, they are more complicated specially if several basins of different characteristics are involved. This paper presents a simple and cheap method of correlation between a set of eighteen morphometic parameters of thirty-two drainage basins from the Northern Littoral of the State of São Paulo, based on the "morphometric susceptibility" of those basins to flood events occurrence. Any number of basins and morphometric parameters are likely to be included. The method permits the identification of homogeneous basins according to their morphometric characteristics and, consequently, their hydrologic behavior. Morphometric susceptibility constitutes an important indicator for flood risk assessments. Therefore, morphometric susceptibility could be used as one of the attributes in methods to identification of hydrologically homogeneous regions for flood frequency analysis and basin regionalization for flood forecasting, specially of drainage basins where hydrologic data are not available.
\end{abstract}

Keywords: Costal drainge, flood, morphometrical susceptibility. 


\section{Introdução}

Em regiões litorâneas tropicais, a passagem de uma frente fria de intensa pluviosidade, principalmente quando combinada aos efeitos de marés astronômicas e meteorológicas elevadas, pode produzir acumulação de águas no interior de uma bacia de drenagem superior àquela que os canais podem suportar, causando inundações e enchentes que duram algumas horas até várias semanas.

Os fatores condicionantes de inundações e enchentes em regiões costeiras são de origem natural e/ou antrópica (Souza, 1998). Os condicionantes naturais são divididos em: climático-meteorológicos (magnitude e freqüência de chuvas associadas a frentes frias, fenômenos climáticos como El Niño e La Niña etc.), geológico-geomorfológicos (substrato geológico, morfometria da bacia de drenagem, solo e cobertura vegetal), flúvio-hidrológicos (hidráulica fluvial, correntes geradas por marés em áreas estuarinas e lagunares etc.) e oceanográficos (influência das marés e da dinâmica de circulação costeira junto à desembocadura fluvial ou lagunar). Os condicionantes antrópicos resultam de intervenções humanas diretas ou indiretas nas bacias de drenagem, podendo ser genericamente agrupados em: uso e ocupação de áreas marginais aos canais de drenagem (águas doces e mixohalinas); modificações na rede de drenagem (aterros, construção de estruturas lineares e barragens; implantação de medidas estruturais para minimizar enchentes, disposição de resíduos sólidos e líquidos em locais inadequados ou nos próprios canais etc.) e modificações nos processos sedimentares naturais e no balanço sedimentar do sistema costeiro.

Estudos de risco a enchentes e inundações têm sido historicamente desenvolvidos por profissionais de várias áreas de atuação, entre eles geólogos, climatólogos, geomorfólogos e engenheiros. A abordagem metodológica desses estudos varia conforme a atribuição profissional de cada um e também a escala de trabalho adotada (Baker et al., 1988; Beven \& Carling, 1989; Cooke \& Doornkamp, 1990; Tucci, 1993; Baker, 1994; Souza, 1998, entre outros). Conseqüentemente, os atributos utilizados para a obtenção da cartografia de risco podem ser muito variados, como por exemplo: hidroclimatológicos (magnitude e freqüência de chuvas, fenômenos climáticos como El Niño etc.), hidrológicos (hidráulica fluvial, correntes geradas por ondas e por marés, circulação estuarina etc.), geológico-geomorfológicos (substrato geológico, morfometria da bacia de drenagem, solo e cobertura vegetal) ou, então, uma mistura de vários deles, obviamente sempre em associação com atributos antrópicos (uso e ocupação, presença de medidas estruturais etc.).

Inúmeros autores têm encontrado fortes correlações entre os parâmetros morfométricos da bacia de drenagem e as características hidrológicas da mesma e, portanto, a sua suscetibilidade em desenvolver inundações e enchentes. Essas correlações, no entanto, são feitas em geral isoladamente, para cada parâmetro, ou para no máximo três ou quatro parâmetros. Isso ocorre porque há dificuldade em se estabelecer intervalos genéricos de referência para classificações de graus de suscetibilidade dessas bacias ao desenvolvimento de inundações. O nível de complexidade aumenta quando várias bacias são analisadas em conjunto, sendo extremamente difícil comparar e interpretar os valores absolutos desses parâmetros entre si.

O presente trabalho apresenta um método analítico do comportamento de um conjunto de dezoito parâmetros morfométricos de bacias de drenagem de regiões costeiras, a partir do qual é possível estabelecer graus de "suscetibilidade morfométrica" dessas bacias ao desenvolvimento de inundações e enchentes.

Os resultados apresentados são provenientes de pesquisas sobre riscos a inundações, enchentes e alagamentos no litoral de São Paulo, desenvolvidas no âmbito do Projeto SIIGAL "Sistema Integrador de Informações Geoambientais para o Litoral do Estado de São Paulo, Aplicado ao Gerenciamento Costeiro" (Souza, 2003). A área de estudo do SIIGAL compreende todos os municípios litorâneos de São Paulo e dois municípios do Vale do Ribeira, totalizando 16 municípios (Figura 1). A escala cartográfica de trabalho é de 1:50.000.

\section{Inundações e Enchentes em Regiões Costeiras}

Inundações e enchentes são problemas geoambientais derivados de fenômenos ou perigos (hazards) naturais de caráter hidrometeorológico ou hidrológico, ou seja, aqueles de natureza atmosférica, hidrológica ou oceanográfica (ISDR, 2002).

As bacias de drenagem em áreas costeiras apresentam uma particularidade geomorfológica importante, que condiciona muito o desenvolvimento de cheias: em geral, as cabeceiras e a maior área de captação das bacias encontram-se em terrenos do embasamento com declividades elevadas a médias, enquanto que o restante da bacia está implantada sobre terrenos de planície costeira, com declividades baixas até nulas. Com isso, os rios de planície costeira recebem enorme volume de água proveniente das encostas, mas o coeficiente de escoamento diminui fortemente devido às baixas declividades e à ação de represamento das águas doces causada pelas marés que adentram os canais estuarinos e lagunares. Portanto, qualquer estudo de suscetibilidade morfométrica em áreas costeiras deve levar em consideração que essas bacias apresentam dois compartimentos geomorfológicos distintos, que devem ser analisados individualmente.

$\mathrm{Na}$ literatura de língua portuguesa há grande controvérsia e, até mesmo, confusão no emprego dos termos enchente e inundação, traduzidos dos termos "flood" e "flooding" e, mais raramente, de "inundation". Em regiões costeiras, devido aos diferentes tipos de processos possíveis, a confusão é ainda maior. 


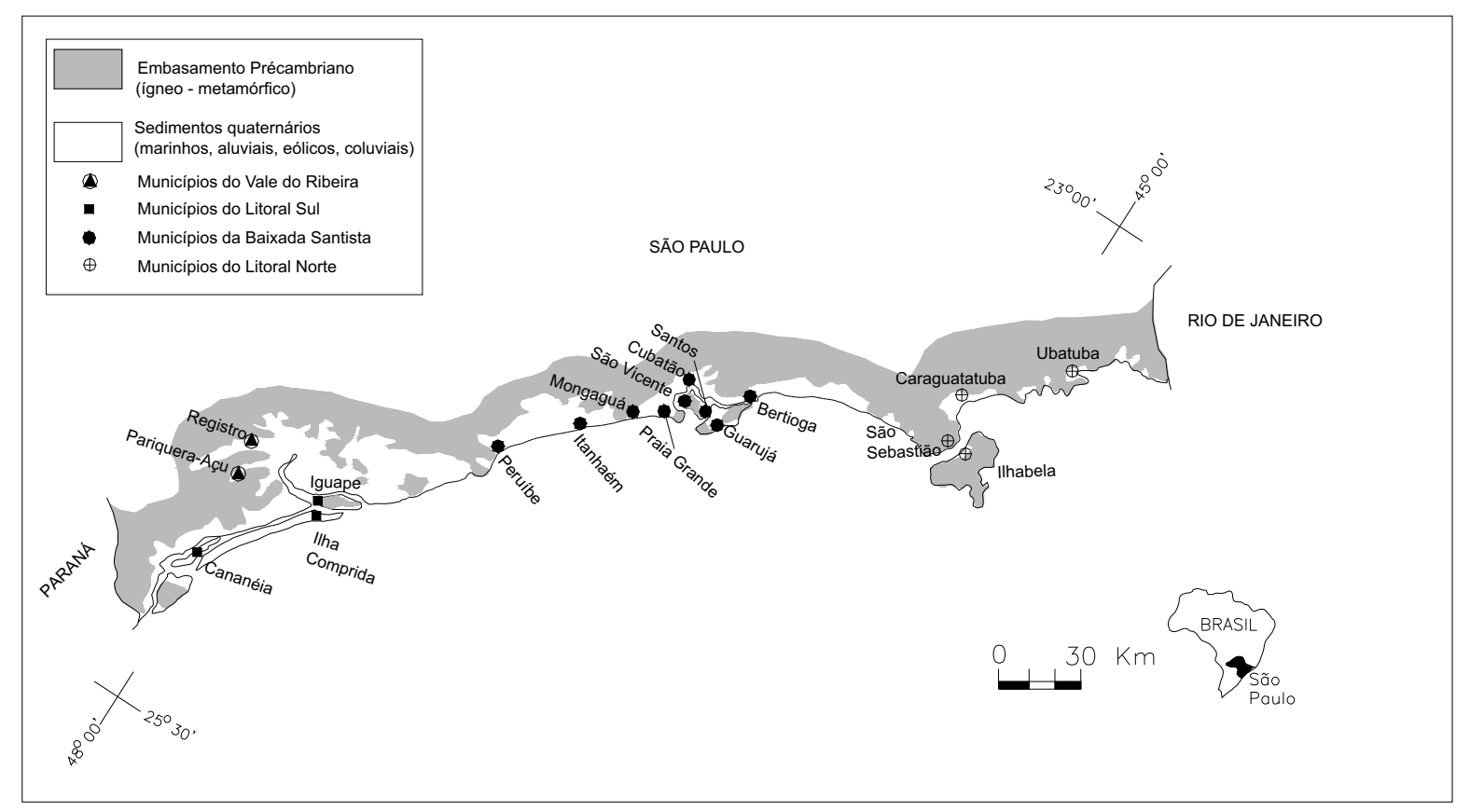

Figura 1. Área de estudo do Projeto SIIGAL

Assim, levando em consideração todos os tipos de processos associados a inundações e enchentes em regiões costeiras, para o Projeto SIIGAL estão sendo adotadas as definições descritas a seguir.

-Inundação costeira (storm surge flooding) causada por ressacas, ou seja, marés meteorológicas em conjunção com marés astronômicas elevadas (marés de sizígia), que afetam praias e estruturas costeiras, terraços marinhos holocênicos frontais e/ou ocupações antrópicas marginais à linha de costa.

-Inundação na planície costeira (riverine flooding) causada por transbordamento de canais fluviais ou de águas mixohalinas (canais estuarinos, de maré e lagunares) sobre terrenos naturais da planície costeira marginais a esses canais (fluxos de alta velocidade zona de passagem da onda de cheia), onde não existem ou são raras as ocupações antrópicas (embora possa haver algum tipo de uso rarefeito e não urbano, como atividades agropecuárias, presença de estruturas e obras lineares, construções isoladas etc.), sendo que a abrangência das áreas invadidas pelas águas é diretamente proporcional à ordem hierárquica do canal.

-Enchente na planície costeira (flood/flooding) causada por transbordamento de canais fluviais ou de águas mixohalinas (canais estuarinos, de maré e lagunares) de águas mixohalinas (canais estuarinos, de maré e lagunares) sobre terrenos com ocupação antrópica marginais a esses -canais (fluxos de alta velocidade zona de passagem da onda de cheia), sendo que a abrangência das áreas invadidas pelas águas é diretamente proporcional à ordem hierárquica do canal, do grau de impermeabilização do solo (função do tipo de uso) e da presença de medidas estruturais de controle e mitigação de enchentes.

-Inundação/Enchente relâmpago (flash flood/flooding) causada por transbordamento de canais fluviais presentes nas baixas encostas, em terrenos naturais ou antropizados, sendo que a abrangência das áreas invadidas pelas águas é bastante restrita devido à baixa ordem hierárquica dos canais e à declividade mais acentuada dos terrenos.

-Alagamentos ocorrem em áreas distantes dos canais fluviais e de maré, sobre terrenos com ocupação antrópica (fluxos de baixa velocidade), em depressões com mínimo coeficiente de escoamento superficial devido à muito baixa declividade natural do terreno, à implantação de obras de engenharia mal dimensionadas, ou outras intervenções antrópicas.

Por essas definições depreende-se que a morfometria de bacias de drenagem é um dos fatores naturais que atuam na predisposição ao desencadeamento de eventos de inundações na planície costeira e inundações relâmpago. 


\section{Morfometria e Comportamento Hidrológico de Bacias de Drenagem}

Horton (1932 apud Horton, 1945) foi o primeiro a fazer estudos quantitativos de bacias de drenagem e a analisar as relações entre as propriedades morfométricas de uma bacia e suas características hidrológicas, incluindo descargas em situações de cheias de várias freqüências $\mathrm{e}$ magnitudes. Seguiram-se muitos outros autores, sistematizando parâmetros morfométricos em bacias hidrográficas da Europa e Estados Unidos, e relacionando alguns deles ao comportamento do escoamento superficial, à descarga fluvial e ao desenvolvimento de inundações e enchentes. Dentre esses autores destacam-se: Horton (1945), Strahler (1952, 1964), Chorley (1957), Chorley et al. (1957), Morisawa (1962), Patton \& Baker (1976), Patton (1988) e Zãvoianu (1985).

De acordo com Cooke \& Doornkamp (1990), os fatores que se interrelacionam e são responsáveis pela ocorrência de eventos de inundação podem ser divididos em transitórios, permanentes e mistos. Os transitórios estão associados à ocorrência de chuvas, taxas de evapotranspiração e grau de saturação do solo. Os fatores permanentes correspondem às características morfométricas da bacia de drenagem e à geologia. Os fatores mistos estão relacionados ao tipo de uso e ocupação do solo.

A análise morfométrica de bacias hidrográficas pode ser entendida em Geomorfologia como processos sistemáticos e racionais, cuja preocupação é a de "medir as formas do relevo", ou seja, a geometria das bacias de drenagem (Horton, 1945).

O fluxo nos canais depende daqueles fatores os quais determinam a quantidade do excesso de chuva e daqueles que influenciam o tempo total que as águas das chuvas levam para percorrer toda a bacia, ou seja, o tempo total de escoamento das águas na bacia (Morisawa, 1962). O excesso de chuva é determinado primariamente pelo clima, a vegetação, a capacidade de infiltração e de estoque superficial de água.

Entre as décadas de 1930 e 1980, parâmetros morfométricos como área e forma da bacia, hipsometria da bacia e comprimento e declividade do canal principal têm sido associados por diversos autores como fatores importantes no controle de parâmetros da unidade hidrográfica e, portanto, no comportamento das hidrógrafas (tempos de duração dos picos de cheias) de enchentes/inundações (Patton, 1988).

Horton (1945) sugeriu que a área, a declividade dos canais e a densidade de drenagem são altamente correlacionadas com a descarga máxima de uma inundação. Para Hack (1957 apud Morisawa, 1962), os fatores geomórficos como comprimento dos canais, forma e gradiente topográfico (declividade) da bacia, bem como as características geológicas tais como tipo de rocha e estrutura, são os que mais influenciam na intensidade do escoamento e na descarga.

Morisawa (1962) concluiu que a descarga e o escoamento superficial (Q) são função principalmente da área (A), do comprimento total dos canais (L), da freqüência de canais de $1^{\mathrm{a}}$ ordem $\left(\mathrm{F}_{1}\right)$, do gradiente ou declividade do canal principal (S), da circularidade (C) da bacia e da taxa de relevo $(\mathrm{Rh})$, de forma que: $\mathrm{Q}=f\left(\mathrm{~A} . \mathrm{L} . \mathrm{F}_{1} .1 / \mathrm{S} .1 / \mathrm{C} .1 / \mathrm{Rh}\right)$.

Boulton (1965 apud Acreman \& Sinclair, 1986) elegeu treze índices morfométricos que influenciam as propriedades hidrológicas. Acreman \& Sinclair (1986) afirmaram que os tipos e as taxas de processos hidrológicos que ocorrem no interior de uma bacia de drenagem podem ser determinados pelas propriedades morfométricas dessa bacia. Segundo eles a área, o comprimento do canal de ordem "n", a declividade do canal de ordem "n" e a densidade de drenagem são os fatores mais determinantes de processos hidrológicos.

Estudos de eventos de inundação/enchente em bacias hidrográficas da Romênia, através de 152 estações de medição de parâmetros hidrológicos revelaram haver uma dependência desses parâmetros com as características morfométricas das bacias de drenagem (Zãvoianu, 1985). Assim, o tempo total de duração das inundações/enchentes (Tt) e o tempo de elevação das águas (Tr) mostraram-se diretamente proporcionais à área da bacia e ao comprimento do canal principal, e inversamente proporcional à declividade média da bacia ou do canal principal. Também encontraram que, para uma mesma área, Tt aumenta em função da diminuição da altitude da bacia (quanto menor a altitude, maior o $\mathrm{Tt}$ ), enquanto que para uma mesma altitude, Tt aumenta em função do aumento da área (quanto maior a área, maior o Tt).

A partir de uma revisão bibliográfica sobre o tema, conclui-se que dentre os inúmeros parâmetros morfométricos descritos na literatura, aqueles que apresentam melhor relação quanto ao desencadeamento potencial de inundações são: ordem hierárquica da bacia; número e freqüência de canais totais e de primeira ordem; tamanho da bacia (área e perímetro totais); comprimento do canal principal (ou da bacia); forma da bacia, fator forma e índice de circularidade; declividade do canal principal e declividade da bacia; densidade hidrográfica e densidade de drenagem; densidade de confluências e relação de bifurcação; taxa de relevo e rugosidade do relevo.

Todos esses parâmetros e sua relação com o escoamento superficial, a vazão e, portanto, seu comportamento nos eventos de inundações encontra-se sinteticamente descrito na Tabela 1.

Áreas de ocorrência potencial de inundações/enchentes relâmpago apresentam, em geral: mais elevados $n^{\circ}$ de rugosidade; fina textura de drenagem (portanto, alta densidade de drenagem, alta densidade hidrográfica, alta freqüência de canais de $1^{\mathrm{a}}$ ordem); mínimo comprimento do canal principal e canais com elevados gradientes (Patton, 1988). Em outras palavras, dentro de uma bacia, quanto menor a ordem hierárquica, maior será a fragmentação dos canais e menor a área de captação e o perímetro dela, portanto maior será a densidade e 


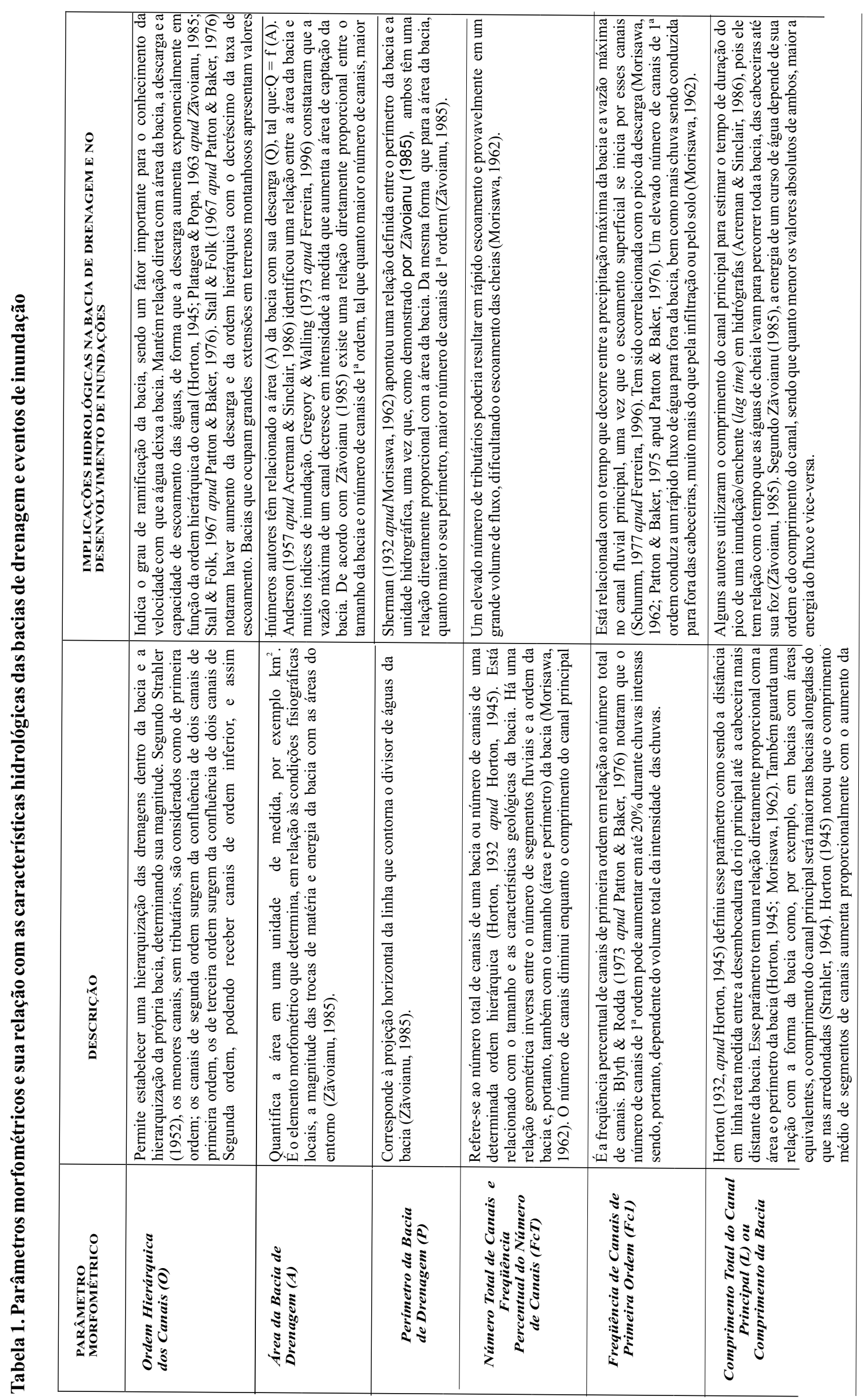




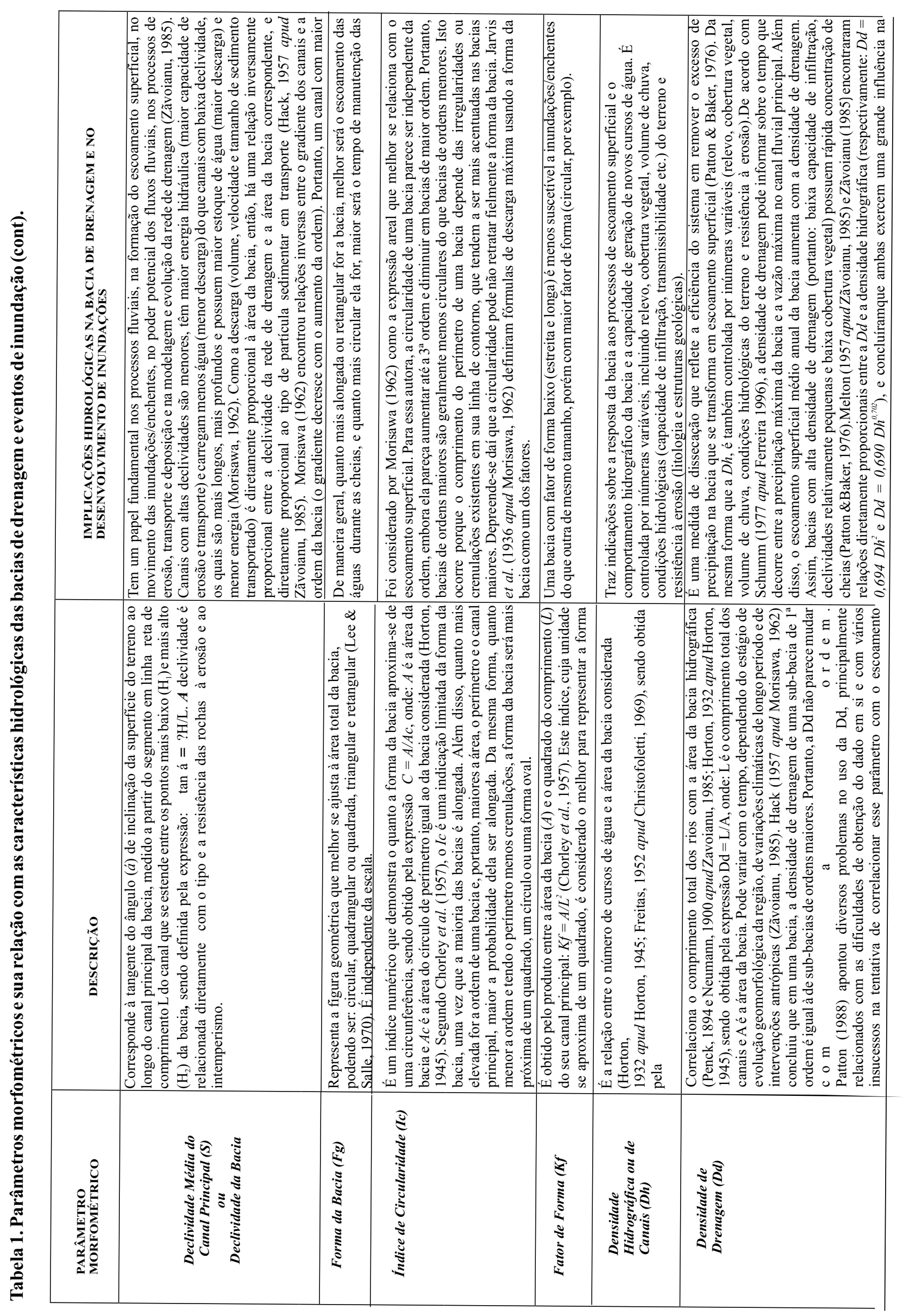




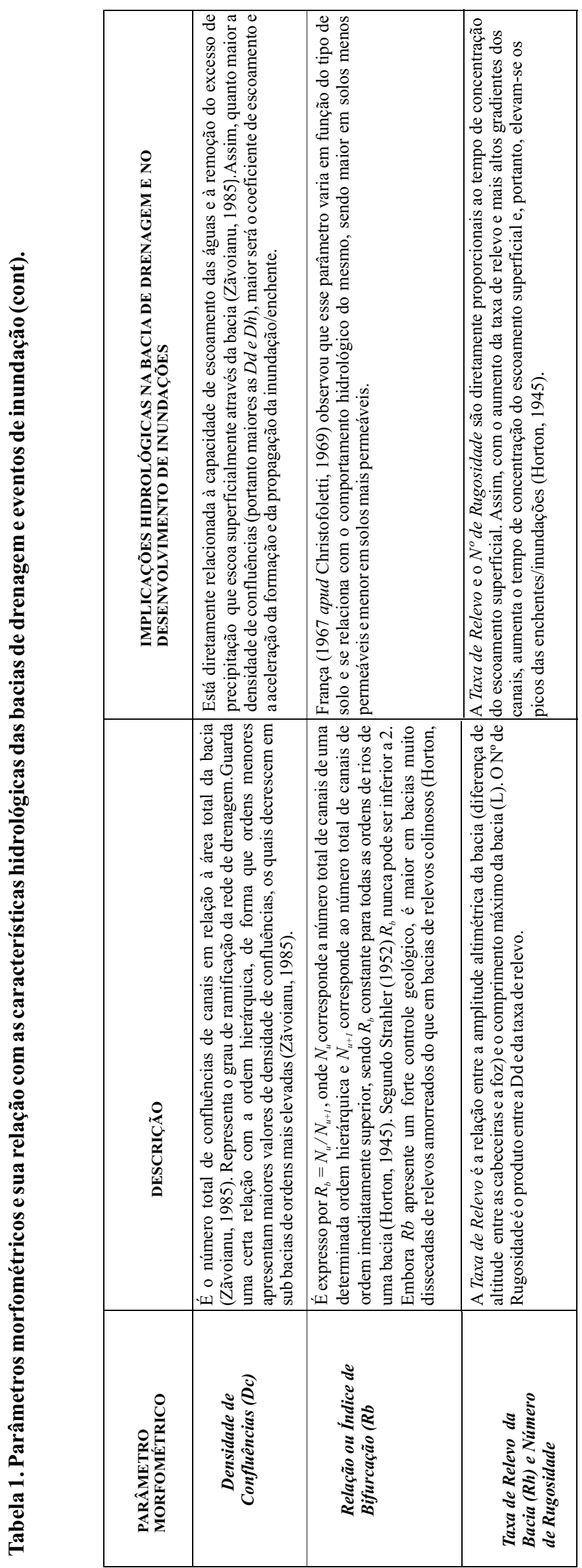


o perímetro dela, portanto maior será a densidade hidrográfica e a densidade de drenagem, aumentando o coeficiente de escoamento e a aceleração da formação e da propagação da inundação/enchente (Zãvoianu, 1985).

\section{Suscetibilidade Morfométrica de Bacias de Drenagem ao Desenvolvimento de Inundações}

Pelo exposto anteriormente é bastante óbvio o papel da morfometria da bacia de drenagem como um importante condicionante natural na determinação do comportamento hidrológico dessa bacia. Em outras palavras, ela é um dos fatores responsáveis pela suscetibilidade natural ao desenvolvimento de Perigos hidrometeorológicos, entre eles as inundações/enchentes. Obviamente, outros fatores também integram essa suscetibilidade natural, entre eles: as características geológicas, os tipos de cobertura vegetal e as características climáticas da bacia de drenagem (Souza, 1998; Souza et al., 2001; Tominga et al., 2001).

O termo Perigo (Hazard) significa "um evento físico, fenômeno natural e/ou induzido por uma atividade humana, potencialmente danoso ou nocivo, que pode causar a perda de vidas, ferimentos, danos a propriedades e bens, interrupção de atividades sociais e econômicas e degradação ambiental" (Varnes, 1984; ISDR, 2002). O Perigo (P) é um dos termos da equação de Risco, cuja expressão adotada nos estudos de inundações/enchentes do Projeto SIIGAL é: $\boldsymbol{R}=\boldsymbol{P} \mathbf{x}$ $\boldsymbol{D} \boldsymbol{p}$, onde $\boldsymbol{D} \boldsymbol{p}$ representa os danos potenciais causados às populações (perdas de vidas, ferimentos, bens), às propriedades e aos ecossistemas. O Perigo envolve também a probabilidade de ocorrência de um fenômeno natural em um determinado período de tempo e em uma dada área (Varnes, 1984), sendo, portanto, função de:

- $\quad$ suscetibilidade (perigo relativo) do meio natural em desenvolver inundações (inundações costeiras, inundações na planície costeira e inundações relâmpagos);

- $\quad$ suscetibilidade ou potencialidade do meio antrópico em induzir enchentes (enchentes na planície costeira e enchentes relâmpago) e alagamentos;

- probabilidade estatística de ocorrência dos eventos (perigo absoluto), que pode ser expresso através do cálculo dos tempos de recorrência ou períodos de retorno dos eventos.

Suscetibilidade natural corresponde ao grau de probabilidade que os atributos naturais têm em condicionar, induzir ou acelerar a ocorrência de um determinado perigo. Propõe-se aqui o conceito de "Suscetibilidade Morfométrica" das bacias de drenagem para definir a parcela de responsabilidade do comportamento geométrico das bacias no desencadeamento de inundações.

Embora os parâmetros morfométricos há muito sejam utilizados nos estudos de suscetibilidade a inundações, a maioria dos autores seleciona alguns poucos parâmetros que considera mais conveniente para estabelecer correlações, e realiza análises integradas entre um número reduzido de não mais do que quatro desses parâmetros. Isto constitui uma grande limitação no emprego da morfometria das bacias de drenagem nesses estudos, já que a interação entre todos os atributos geométricos da bacia e como eles operam em conjunto é que são responsáveis pelo comportamento hidrológico dessa bacia. Por outro lado, quando a análise envolve mais do que duas bacias, tentar correlacionar valores absolutos de seus parâmetros morfométricos é tarefa árdua e complexa. Neste sentido, não é possível estabelecer intervalos genéricos com os valores absolutos dos parâmetros morfométricos para hierarquizar graus de suscetibilidade, a menos que algum dos parâmetros seja fixo como, por exemplo, a área ou a ordem hierárquica das bacias.

O método de obtenção da Suscetibilidade Morfométrica de bacias apresentado aqui é um método semi-qualitativo, que integra o maior número possível de parâmetros morfométricos. É bastante fácil de ser aplicado, rápido e econômico. Pode ser utilizado para qualquer número de parâmetros morfométricos, embora seja recomendado o maior número possível. É especialmente útil quando se quer comparar várias bacias de uma determinada região.

A definição do número de classes de suscetibilidade dependerá dos objetivos da pesquisa e do nível de informação disponível sobre as bacias, em geral podendo variar entre três e cinco classes ou graus, como por exemplo suscetibilidades variando de: Muito Alta a Muito Baixa; Alta a Baixa; Muito a Muito Pouco Suscetível; Suscetível a Pouco Suscetível etc. Este é um critério qualitativo e relativo, ou seja, cada parâmetro morfométrico é classificado relativamente em função dos intervalos de valores obtidos para o conjunto de todas as bacias analisadas.

Para o Projeto SIIGAL, a escala de suscetibilidade morfométrica adotada é de três classes: Alta, Média e Baixa.

A obtenção da classificação da Suscetibilidade Morfométrica das bacias de drenagem envolve os passos descritos a seguir.

- Identificar e selecionar os parâmetros morfométricos a serem integrados, respeitando sempre as características geológicas e geomorfológicas das bacias de drenagem. O número de parâmetros morfométricos e o número de bacias a serem correlacionados entre si são ilimitados.

- Efetuar os cálculos dos valores dos parâmetros morfométricos selecionados com base em cartas topográficas, preferivelmente 
em escala 1:50.000, inserindo os dados em planilhas.

- Como cada parâmetro morfométrico analisado apresentará uma série de valores dependentes das características das bacias analisadas (valores estes que podem ser próximos entre si ou bastante heterogêneos), então será necessário dividir essa série em intervalos homogêneos de valores, tantos quanto o número de classes de suscetibilidade previamente estabelecidas. No caso apresentado são, portanto, três intervalos. Devem ser identificados inicialmente os valores máximo e mínimo e a média aritmética da série. Eventuais valores anômalos que estejam muito dispersos dessa média devem ser excluídos da operação de divisão dos intervalos, evitando erros de classificação. Esses valores anômalos, que sempre serão extremos da série (muito maiores ou muito menores), serão posteriormente integrados aos intervalos de valores máximos ou mínimos das classes de suscetibilidade.

- Identificados os intervalos, o passo seguinte é classificar cada um em função do seu grau relativo de suscetibilidade, com base nos conceitos apresentados anteriormente. Para facilitar a classificação final de cada bacia, utiliza-se um artifício matemático tal que para cada classe de Suscetibilidade é atribuída um certo número de pontos, como por exemplo: $\mathrm{ALTA}=3$ pontos; MÉDIA $=2$ pontos; $\mathrm{BAIXA}$ $=1$ ponto. Por exemplo, supondo-se que o parâmetro "Forma geométrica" das bacias varie entre circular, triangular, quadrada e retangular. Pelo exposto no capítulo anterior, as bacias circulares são as mais suscetíveis (ALTA) a inundações e as retangulares são as menos (BAIXA) suscetíveis, ficando as triangulares e quadradas em nível intermediário (MÉDIA). Portanto, a pontuação para a Suscetibilidade Morfométrica quanto ao parâmetro "Forma" seria: bacias circulares $=3$ pontos; bacias triangulares e quadrangulares $=$ 2 pontos; e bacias retangulares $=1$ ponto. $\mathrm{O}$ mesmo procedimento dever ser adotado para os parâmetros numéricos.

- Obtidas todas as pontuações de suscetibilidades individuais de cada parâmetro para as " $n$ " bacias, procede-se à somatória do número total de pontos para cada bacia. Assim, o número mínimo de pontos será " $n$ " e o número máximo será " $3 \mathrm{n}$ " (para o caso de se adotar três classes de suscetibilidade). $\mathrm{Na}$ seqüência, os procedimentos são os mesmos descritos no passo $\mathrm{n}^{\circ} 3$, pois também a série de valores de pontos totais deverá ser dividida em 3 intervalos (excluindo-se os valores dispersos da média), que ao final serão também classificados quanto ao grau de suscetibilidade: ALTA, MÉDIA e BAIXA.
Na hipótese de se adotar 4 ou 5 classes, a pontuação adotada para cada classe seguirá o mesmo padrão.

\section{5. Área de Estudo}

Neste trabalho são apresentadas as 32 bacias de drenagem mapeadas no Litoral Norte, todas elas a partir da $3^{\mathrm{a}}$ ordem hierárquica (figuras $2 \mathrm{a}$ e 2b). Esta escolha em relação à ordem hierárquica reside no fato de que, de acordo com Souza (1998), no município de São Sebastião (Litoral Norte) as enchentes/inundações ocorrem em bacias a partir da $3^{a}$ ordem. Assim, uma vez que as menores bacias encontram-se nesse município, o mesmo pode ser estendido ao restante do Litoral Norte paulista.

As bacias de drenagem do Litoral Norte escoam através de dois compartimentos geomorfológicos distintos e bem individualizados nas imagens de satélite das figuras $2 \mathrm{a}$ e $2 \mathrm{~b}$ : a Serra do Mar (borda de planalto e escarpamento estrutural) e a Planície Costeira. As cabeceiras dessas bacias e, em geral, a maior área de captação das mesmas encontram-se em terrenos bastante estruturados do embasamento ígneo-metamórfico precambriano-mesozóico, que suporta o conjunto orográfico da Serra do Mar, ou seja, a borda do escarpamento do Planalto Atlântico. O relevo apresenta rugosidade e amplitude elevadas, definindo um padrão de drenagem denso, com rios curtos e encaixados nas estruturas geológicas. No setor de encosta encontram-se mais de $60 \%$ dos canais de todas as bacias e mais de $70 \%$ dos canais de primeira ordem das mesmas. Ao deixarem as encostas íngremes, os rios passam a percorrer terrenos da planície costeira formados por sedimentos quaternários (principalmente marinhos, aluvionares e coluvionares de baixada), com lençol freático raso $(=2 \mathrm{~m})$ a superficial e declividades baixas até nulas (inferiores a $5^{\circ}$ de acordo com Souza, 1998), para então atingirem a linha de costa, onde encontram praias de diferentes estados morfodinâmicos.

As bacias de drenagem do Litoral Norte são muito atingidas por chuvas orográficas, pois as altitudes da Serra do Mar atingem até mais de 1.000 $\mathrm{m}$. Esse tipo de regime pluvial é propício ao desenvolvimento de inundações e enchentes relâmpago, as quais, nas bacias menores, atingem não somente os sopés da Serra do Mar, mas podem alcançar a linha de costa. Nesses eventos é comum a ocorrência conjunta de fluxos de detritos e de lama, como já observado na Bacia do Rio São Francisco (B22), entre outras.

Estudos sobre o regime climático do Litoral Norte para os últimos 30 anos (Sant'Anna Neto et al., 2003) revelam que o padrão pluviométrico habitual para a região varia de 1300 $1400 \mathrm{~mm} /$ ano na área urbana do município de São Sebastião (localizada no interior do Canal de Sebastião, à retaguarda da Ilhabela) até $>3000$ $\mathrm{mm} /$ ano nas regiões mais elevadas da Serra do Mar 


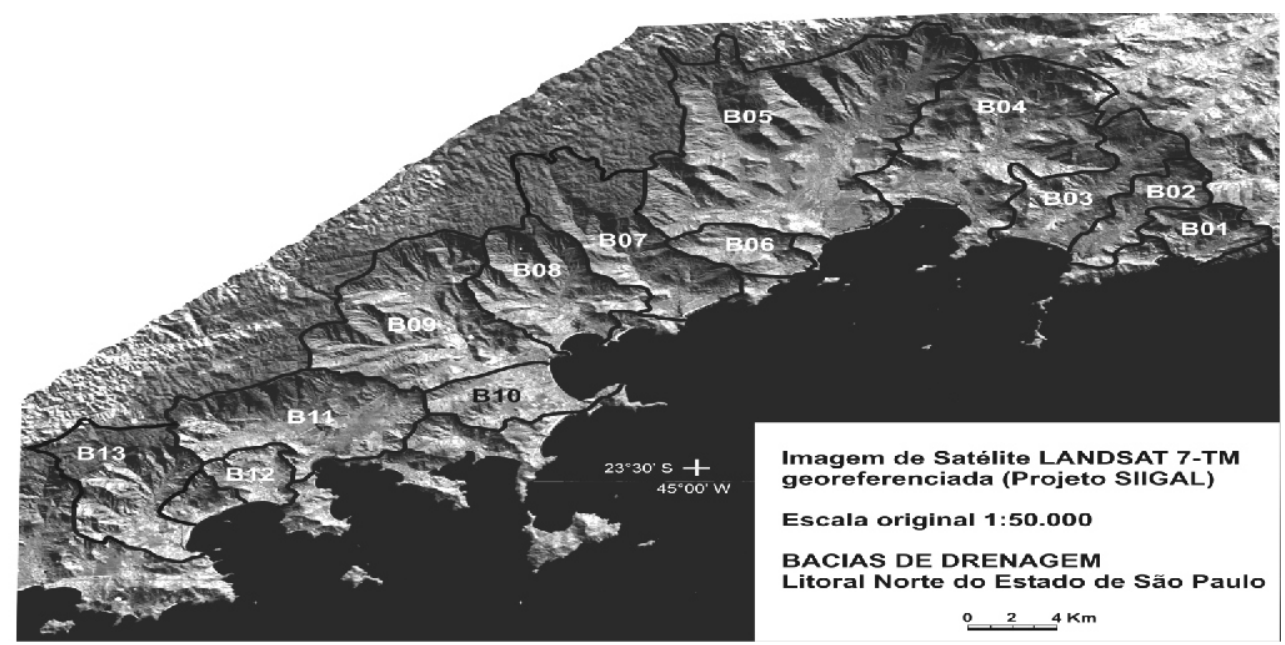

Figura 2a. Bacias de drenagem dos municípios de São Sebastião, Ilhabela e Caraguatatuba delimitadas em imagens de satélite

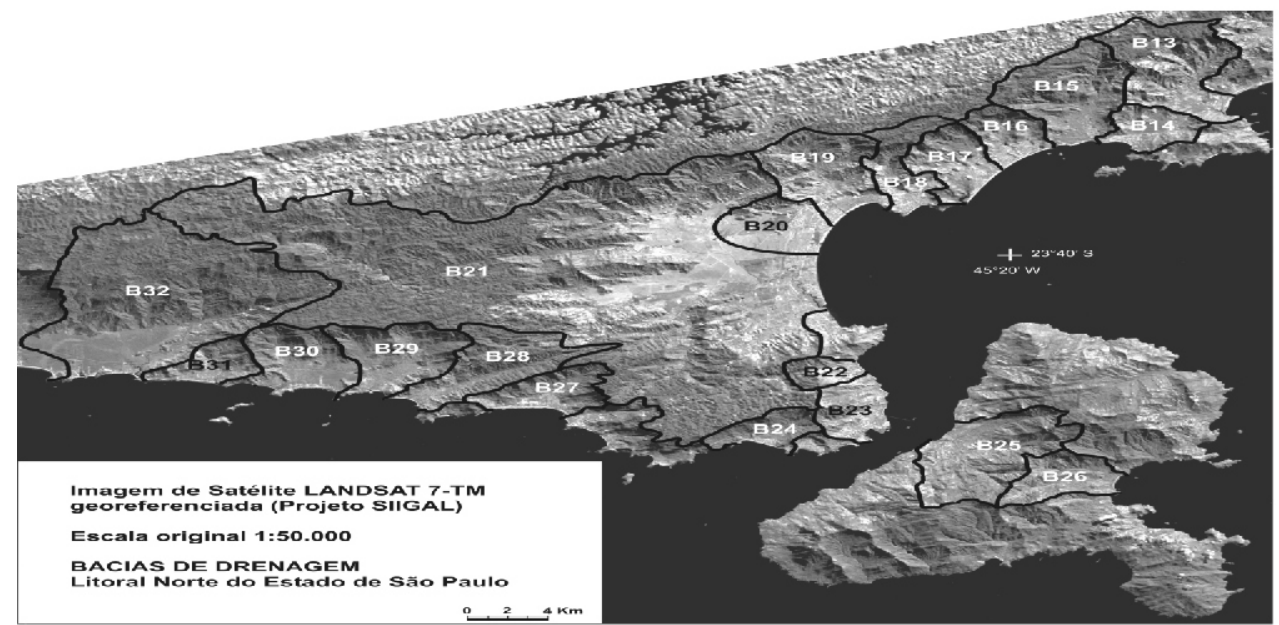

Figura 2b. Bacias de drenagem do município de Ubatuba delimitadas em imagens de satélite

(Ubatuba e Caraguatatuba). Esses valores podem atingir, respectivamente, índices $>1650 \mathrm{~mm} / \mathrm{ano}$ e $>3500 \mathrm{~mm} / \mathrm{ano}$. Da mesma forma, o índice de variabilidade climática também é alto para toda a região, exceto na planície costeira de Caraguatatuba, onde é médio.

Assim, pode-se supor que a maioria dessas bacias é naturalmente suscetível ao desenvolvimento de inundações, uma vez que os rios da planície não têm competência para escoar facilmente todo o grande volume de água que sai das encostas, que se soma ao excedente que está sendo despejado nos vales principais da planície costeira e às águas das preamares que adentram esses rios. Note-se bem que pode haver também um represamento das águas das cheias junto à linha de costa, devido à presença de zonas de sotamar de células de deriva litorânea nas desembocaduras fluviais (Souza, 1998).

Os dois compartimentos geomorfológicos que integram essas bacias apresentam comportamentos hidrológicos bastante diferentes entre si, que responderão de maneira diversificada em relação aos coeficientes de escoamento e de aceleração da formação e da propagação de inundações/enchentes. Por isso, devem ser tratados de maneira independente quanto a alguns atributos morfométricos.

São raros os dados hidrológicos para as bacias do Litoral Norte de São Paulo, sendo que os únicos disponíveis correspondem a curtos períodos de medições de vazão (em geral 1 ano) em alguns poucos rios, medições estas destinadas a cálculos para construção de captações de água para o consumo humano de pequenos núcleos urbanos.

\section{Resultados Obtidos}

Os parâmetros morfométricos selecionados para a obtenção da Suscetibilidade Morfométrica das bacias de drenagem do litoral paulista são: Ordem Hierárquica (O) segundo Strahler (1952), Forma da bacia (Fg), Fator Forma (Kf), Comprimento do Canal Principal (L), Área da bacia (AT), Área da bacia na Encosta (AEnc), Área da bacia na Planície Costeira (APC), Perímetro da bacia (P), Freqüência de Canais Totais na Encosta (FcEnc) e na Planicie 
Costeira (FcPC), Freqüência de Canais de $1^{a}$ Ordem $(F c 1)$, Declividade média do Canal Principal (S), Densidade Hidrográfica Total (DhT), na Encosta (DhEnc) e na Planície Costeira (DhPC) e Densidade de Confluências Total (DcT), na Encosta (DcEnc) e na Planície Costeira (DcPC).

A partir de todas as relações apontadas e discutidas anteriormente, pode-se dizer que a vazão e o escoamento superficial e, portanto, a Suscetibilidade Morfométrica ( $\boldsymbol{S M}$ ) das bacias de drenagem são funções ora direta, ora inversamente proporcionais a cada um dos parâmetros morfométricos apresentados, tal que:

$S M=f(O . F g . K f . A T . A E n c . A P C . P . L . F c E n c$. FcPC. Fc1. DhT. DhEnc. DhPC. DcT . DeEnc. DcPC. 1/S).

A Tabela 2 mostra os resultados dos parâmetros morfométricos obtidos para as 32 bacias de drenagem estudadas.

O índice de circularidade não foi utilizado devido às limitações já apresentadas anteriormente e, também, porque a análise do coeficiente de similaridade entre os todos parâmetros para todas as bacias do Litoral Norte, mostrou que esse parâmetro não tem correlação alguma com os demais. Da mesma forma, a densidade de drenagem não foi utilizada, sendo adequadamente substituída pela densidade hidrográfica e a densidade de confluências. Também não faria sentido usar os parâmetros de taxa de relevo e número de rugosidade uma vez que as unidades geológico-geomorfológicas encosta e planície costeira estão sendo avaliadas individualmente.

As formas das bacias estão sendo representadas pela "forma geométrica" (percepção visual) e pelo "fator forma". Na verdade, como pode ser constatado na Tabela 2, ambos parecem se complementar. As discrepâncias observadas em relação aos dois valores e principalmente em relação aos valores do fator forma podem ser explicadas pelas acentuadas crenulações que marcam os limites das bacias no setor encosta (embasamento) e as elevadas sinuosidades (meandramentos) dos rios principais na planície costeira, ambos mascarando os valores reais do fator forma.

As declividades médias foram calculadas automaticamente através do programa MapInfo, com medidas efetuadas entre a desembocadura fluvial e o ponto mais elevado do canal principal no divisor de águas da bacia. Nas cartas topográficas em escala 1:50.000 existe uma grande limitação na obtenção de declividades na planície costeira, uma vez que não existem curvas de nível, mas apenas alguns poucos pontos cotados. O maior segmento dos canais principais encontra-se nas planícies costeiras, onde as declividades são muito baixas até nulas $\left(=2^{\circ}\right.$ segundo Souza, 1998). Nas encostas as declividades variam entre 20 e $47^{\circ}$ (Souza, 1998). Por essas razões as declividades médias desses canais serão sempre inferiores a $20^{\circ}$ (Tabela 2 ).
No Litoral Norte a menor bacia é a do Rio São Francisco (São Sebastião), de $3^{\mathrm{a}}$ ordem, com área total de $5,88 \mathrm{~km}^{2}$, perímetro de $9,97 \mathrm{~km} \mathrm{e}$ comprimento do canal principal de $2,65 \mathrm{~km}$, cuja declividade média é de $12^{\circ}$. A maior bacia é a do Rio Juqueriquerê (Caraguatatuba), única de $7^{\mathrm{a}}$ ordem nesse trecho do litoral paulista, com área total de $385,62 \mathrm{~km}^{2}, 135,25 \mathrm{~km}$ de perímetro e comprimento do canal principal de $39,50 \mathrm{~km}$, cuja declividade média é de $10^{\circ}$.

A Tabela 3 mostra os resultados obtidos para a classificação das suscetibilidades morfométricas das bacias.As maiores somatórias de pontos (37 a 43) foram obtidas para as bacias dos rios: Iriri-Ubatumirim-Onças, PurubaQuiririm (Ubatuba), Juqueriquerê (Caraguatatuba), Perequê (Ilhabela) e Una (São Sebastião). As menores somatórias (22 a 24) foram obtidas para as bacias dos rios: Perequê AçuIndaiá, Lagoa-Acaraú (Ubatuba), Bacuí, Massaguaçu (Caraguatatuba), Centro de São Sebastião e Maresias (São Sebastião). A média das somatórias obtidas é de 30 pontos, sendo que em 21 bacias a somatória manteve-se entre 25 e 35 pontos.

As bacias com Alta Suscetibilidade ao desenvolvimento de inundações/enchentes são as dos rios: Camburi/Córrego Duas Irmãs (1), das Bicas (2), Fazenda-Fazendinha (3), IririUbatumirim-Onças (4), Puruba-Quiririm (5), Prumirim (6) (Ubatuba), Juqueriquerê (21) (Caraguatatuba), Perequê (25) (Ilhabela), São Francisco (22), Guaecá (24) e Una (32) (São Sebastião). É interessante notar que a maior e a menor bacia da região encontram-se neste grupo. As bacias de Alta suscetibilidade têm as seguintes características: a ordem hierárquica varia de 3 a 7 (seis bacias de ordens 3 e 4; quatro bacias de ordem 5 e uma bacia de ordem 7); duas bacias são circulares, oito são retangulares e uma é triangular; o fator forma varia de 0,25 a 0,84 ; o comprimento do canal principal varia de 2,65 a 39,5 km (a maior e a menor bacia da área de estudo); os perímetros variam entre 9,97 e $135,25 \mathrm{~km}$; as áreas nas encostas são mais do que 5 vezes maiores do que nas planícies costeiras; a freqüência de canais nas encostas são maiores do que $59 \%$ e até $94,87 \%$ (Rio Juqueriquerê); a freqüência de canais de $1^{\text {a }}$ ordem é maior do que $72 \%$ e menor do que $96 \%$ (Rio Perequê), sendo que em nove bacias predominam valores acima de $77 \%$ e também são raros os canais de $1^{\mathrm{a}}$ ordem nas planícies costeiras; as declividades médias dos canais principais variam entre 8 e $14 \%$, embora a média seja de $11^{\circ}$; sete bacias possuem densidade hidrográfica maior na planície costeira e nove bacias possuem densidade de confluência maior na planície costeira. As quatro bacias com densidade hidrográfica na encosta são: Fazenda-Fazendinha, Puruba-Quiririm, Juqueriquerê e Una.. As duas bacias com densidade de confluência maior na encosta são: Puruba-Quiririm e Juqueriquerê. 
青乙 =

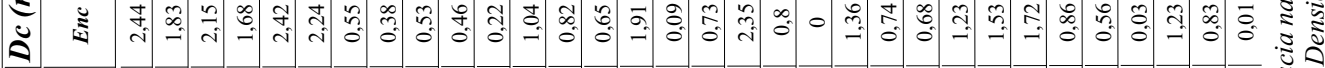

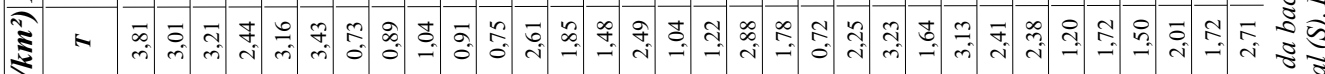

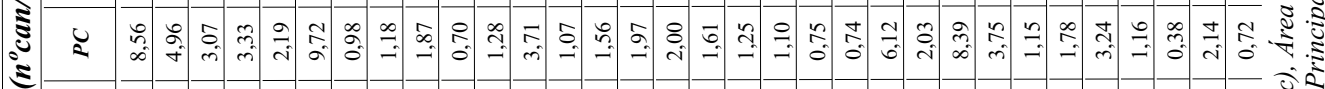

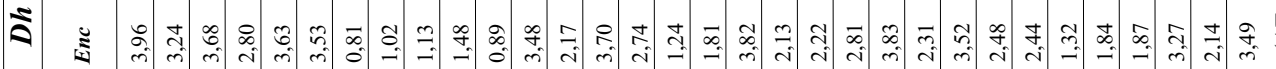

意

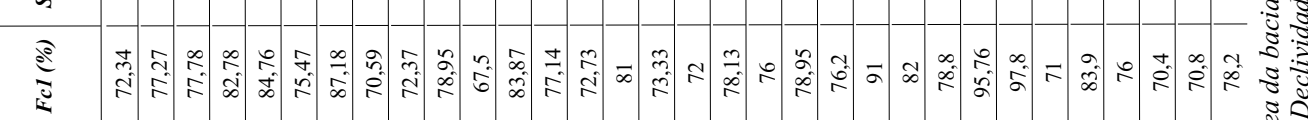

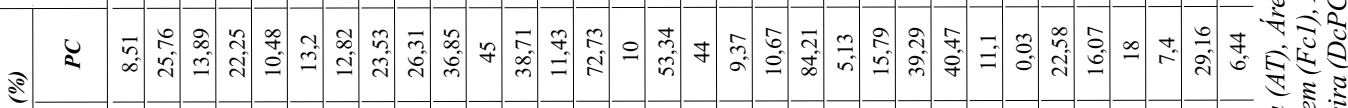

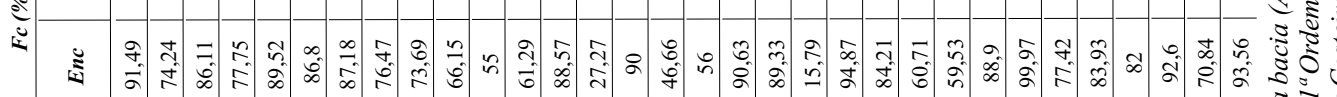

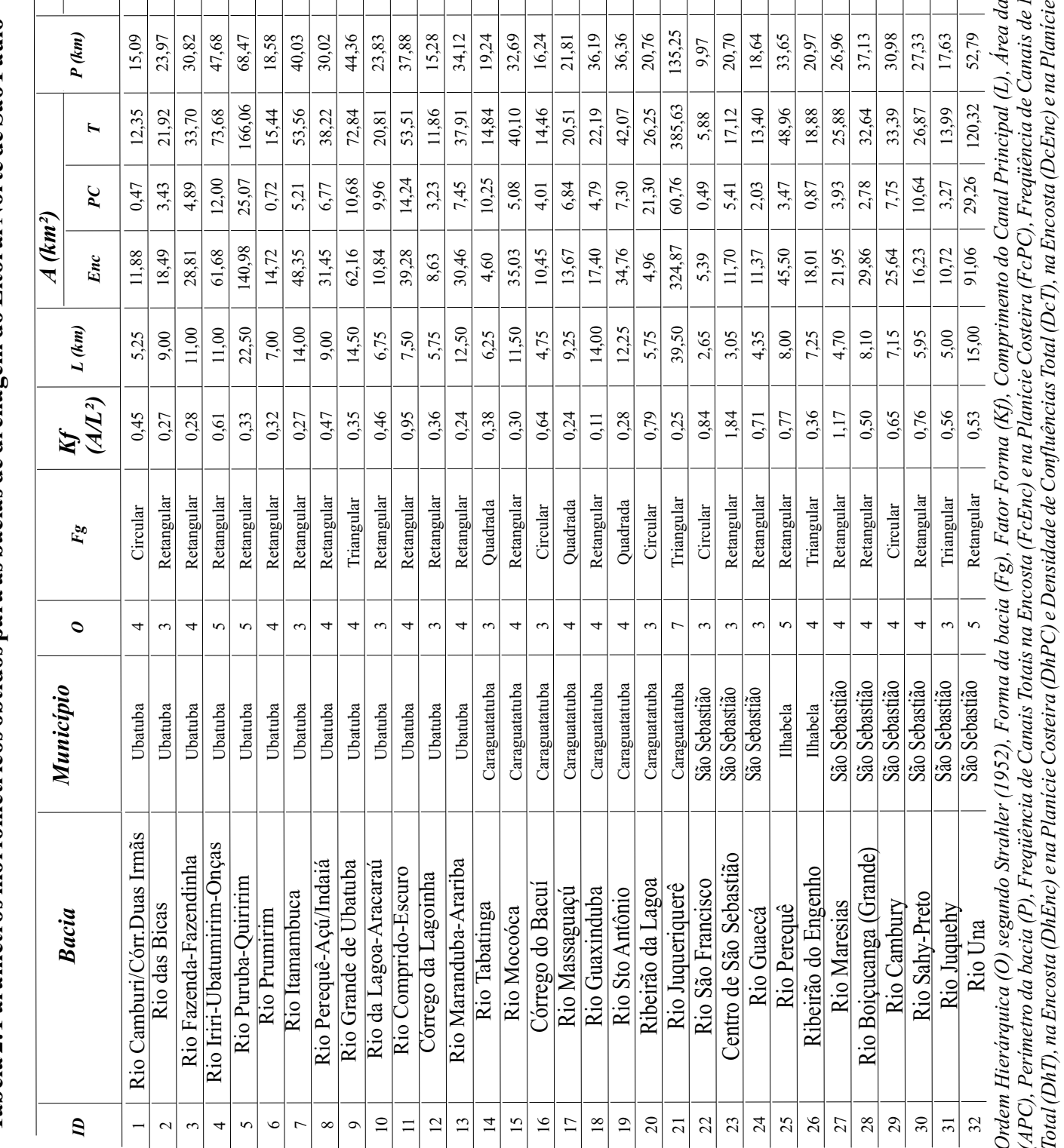




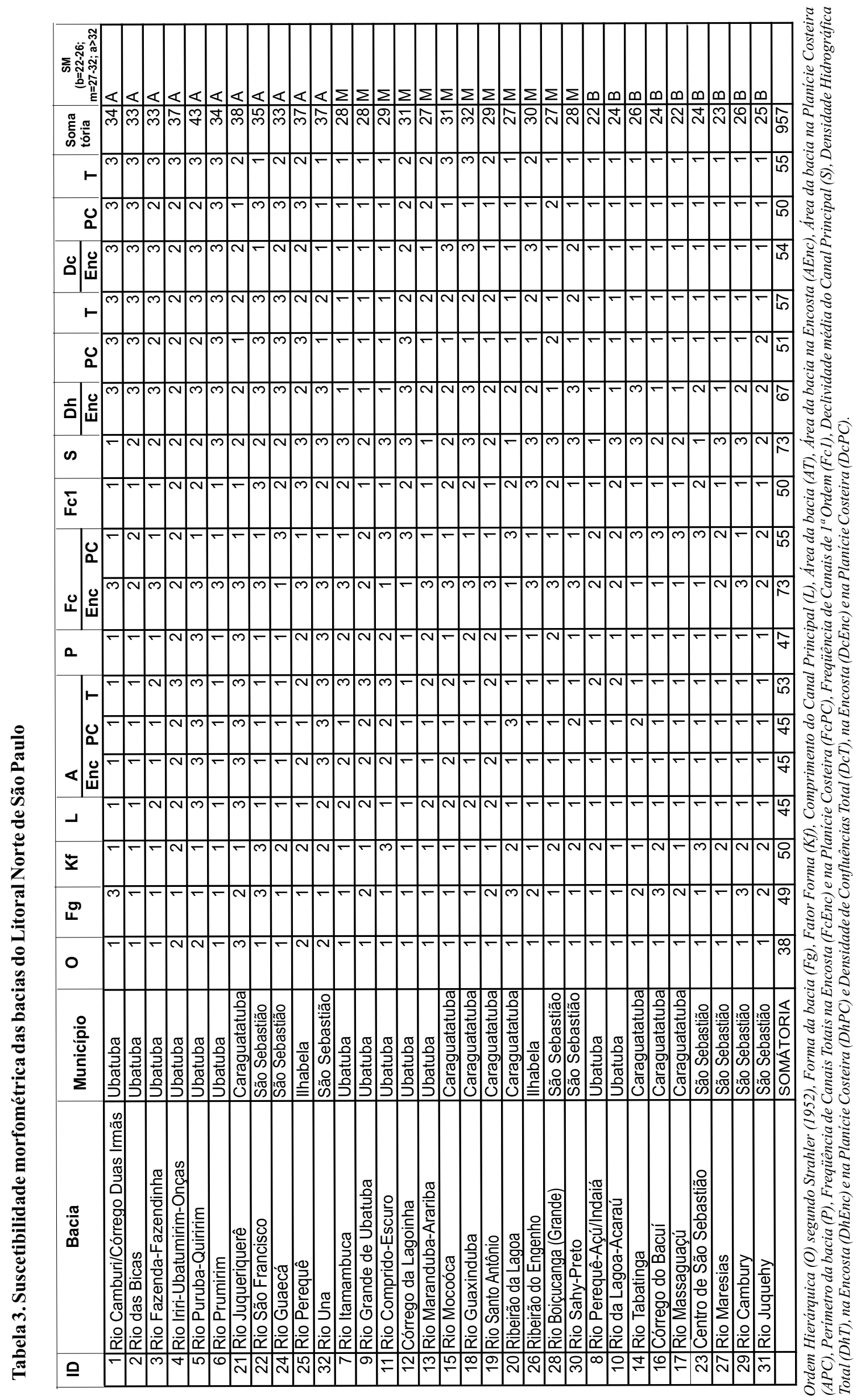


Essas relações ocorrem devido à elevada freqüência de canais e à enorme área de captação nas encostas dessas bacias.

As bacias com Média Suscetibilidade são as dos rios: Itamambuca (7), Grande de Ubatuba (9), Comprido-Escuro (11), Córrego da Lagoinha (12), Maranduba-Arariba (13), Mocoóca (15)(Ubatuba), Guaxinduba (18), Santo Antônio (19), Ribeirão da Lagoa (20) (Caraguatatuba), Ribeirão do Engenho (26) (Ilhabela), Boiçucanga (28), Sahy-Preto (30) (São Sebastião). No grupo de bacias com Média suscetibilidade as características são: nove bacias são de $4^{\mathrm{a}}$ ordem e três são de $3^{\mathrm{a}}$ ordem; oito bacias têm formas retangulares, duas triangulares, uma quadrangular e uma circular; o fator forma varia de 0,11 a 0,95 ; o comprimento dos canais principais varia de 5,75 a 14, $50 \mathrm{~km}$; as áreas nas encostas são muito maiores que na planície, à exceção da bacia do Ribeira da Lagoa, onde a área da planície é maior do que na encosta; a área total das bacias varia entre 11,86 e $72,84 \mathrm{~km}^{2}$, o perímetro varia entre $15,28 \mathrm{e}$ $44,36 \mathrm{~km}$; a freqüência de canais é muito maior na encosta (55 até $99,97 \%$ ) do que na planície, exceto no Ribeira da Lagoa (84,21\%); a freqüência de canais de $1^{\text {a }}$ ordem é elevada $(67,5$ a $97,8 \%)$; a declividade dos canais principais vai de 8 até $15^{\circ}$; a densidade hidrográfica na encosta é de 0,81 (Rio Itamambuca) a 3,82 (Rio Guaxinduba), e na planície é de 0,38-3,71 (maior valor na bacia do Rio Boiçucanga e menor na do Rio Sahy-Preto); a densidade de confluências na encosta varia de zero (Ribeirão da Lagoa) até 2,35 (Rio Guaxinduba), enquanto na planície costeira vai de 0,47 (SahyPreto) a 3,41 (Córrego da Lagoinha).

As bacias com Baixa Suscetibilidade são as dos rios: Perequê-Açu/Indaiá (8), Lagoa-Acaraú (10) (Ubatuba), Tabatinga (14), Córrego do Bacuí (6) (Caraguatatuba), Massaguaçu (17), Centro de São Sebastião (23), Maresias (27), Cambury (29) e Juquehy (31) (São Sebastião). As bacias deste grupo têm as seguintes características: cinco bacias são de $3^{\mathrm{a}}$ ordem e quatro são de $4^{\mathrm{a}}$ ordem; ocorrem todas as formas, com predominância das retangulares (seis bacias); o fator forma variou entre 0,24 (Massaguaçu) e 1,84 (Centro de São Sebastião); os comprimentos dos canais principais são em geral pequenos, variando entre 3,05 e $9,25 \mathrm{~km}$; os perímetros também são pequenos (são em geral bacias pequenas), variando entre 16,24 e $30,98 \mathrm{~km}$; as áreas totais são também pequenas, variado entre $13,99 \mathrm{~km}^{2}$ (Juquehy) e 38,22 $\mathrm{km}^{2}$ (PerequêAçu/Indaiá), mas com média de $22,14 \mathrm{~km}^{2}$; as áreas das encostas são em geral três vezes superiores às das planícies; as freqüências dos canais na encosta embora geralmente maiores do que na planície costeira (exceto nas bacias dos rios Tabatinga e Bacuí), predominando valores entre 56 e $78 \%$; as freqüências de canais de $1^{\text {a }}$ ordem variam entre 70,59 e $82 \%$; as declividades dos canais principais variam entre 3 e $14^{\circ}$, embora os valores médios sejam de $10^{\circ}$; as densidades hidrográficas dos setores encosta e planície costeira apresentam valores muito próximos, sendo pouco maiores apenas nas planícies costeiras das bacias dos rios Perequê-Açu/Indaiá, Bacuí e Maresias; a densidade de confluências, por sua vez, é sempre maior nas planícies costeiras que nas encostas, à exceção da Bacia do Centro de São Sebastião.

Comparando as bacias de Alta e Baixa suscetibilidades morfométricas, pode-se dizer que, em geral, os valores dos parâmetros morfométricos apresentam-se maiores nas bacias de Alta suscetibilidade. Nas bacias de Média suscetibilidade ocorrem sempre situações intermediárias entre ambas.

Analisando os resultados das tabelas 2 e 3, conclui-se que 14 parâmetros controlam são os que mais as variações de suscetibilidade morfométrica nas bacias analisadas, a saber: densidade hidrográfica $(D h T, D h E n c$ e $D h P C)$, densidade de confluências $(D c T, D c E n c$ e $D c P C)$, declividade média do canal principal $(S)$, freqüência de canais de $\mathbf{1}^{\text {a }}$ ordem $(F c l)$, freqüência de canais totais $(F c E n c$ e $F c P C$ ) e o tamanho das bacias (ordem $O$; área - $A$, perímetro $P$ e comprimento do canal principal $-L$ ).

Nas bacias de Alta suscetibilidade a DhEnc varia entre 2,8-3,96 canais $/ \mathrm{km}^{2}$, contra 1,02-3,7 canais $/ \mathrm{km}^{2}$ nas bacias de Baixa suscetibilidade; a $D h P C$ varia de $0,72-9,72$ canais $/ \mathrm{km}^{2}$ nas bacias de Alta suscetibilidade, contra $0,7-2,03$ canais $/ \mathrm{km}^{2}$ nas bacias de baixa suscetibilidade. A $D c E n c$ de bacias de Alta suscetibilidade varia de 0,01-2,44 confluências $/ \mathrm{km}^{2}$, enquanto nas bacias de Baixa suscetibilidade varia de $0,03-0,86$ confluências $/ \mathrm{km}^{2}$; nas planícies costeiras de bacias com Alta suscetibilidade a $D c P C$ varia de 0,99-6,9 confluências $/ \mathrm{km}^{2}$, enquanto nas bacias de Baixa suscetibilidade varia de 0,56-1, 75 confluências $/ \mathrm{km}^{2}$.a de $0,56-1,75$ confluências $/ \mathrm{km}^{2}$.a suscetibilidade apresentam $D h T$ e $D c T$ maiores do que as de Média, as quais, por sua vez, são maiores dos que as de Baixa suscetibilidades.

Os valores de $S$ são geralmente mais baixos ou médios nas bacias de Alta suscetibilidade e maiores nas bacias de Baixa.

As $F c 1$ são sensivelmente menores nas bacias de Baixa suscetibilidade $(70,59-82 \%)$ do que nas de Alta suscetibilidade (72,34-95,76).

Nas bacias de Alta suscetibilidade a $F c$ é maior na encosta e menor na planície costeira; enquanto que nas bacias de Baixa suscetibilidade ocorre o inverso, ou seja, a $F c$ é maior na planície e menor na encosta.

Em geral, as bacias de Alta suscetibilidade são as maiores, apresentando maiores $O, A, P$ e $L$; inversamente, as bacias de Baixa suscetibilidade apresentam menores $O, A, P$ e $L$.

É importante ressaltar que além das tendências observadas isoladamente em relação ao comportamento de cada um desses 14 parâmetros, a conjunção dessas tendências é que deve ser a principal responsável pela magnitude da suscetibilidade dessas bacias.

Todas as tendências observadas em relação aos nove parâmetros acima coadunam com as 
esperadas, apontadas na revisão bibliográfica apresentada no item anterior. Apenas forma e fator forma não apresentaram muitas tendências. A explicação para isso poderia residir no fato de que essas bacias possuem perímetros bastante crenulados e alta sinuosidade de canais, não sendo possível obter-se uma medida fiel para a forma da bacia, independentemente do índice utilizado.

\section{Validação Estatística do Método}

Mesmo tendo sido os resultados bastante convergentes com a literatura, optou-se por uma melhor averiguação da classificação através de um teste estatístico.

O parâmetro estatístico escolhido é o coeficiente de similaridade que, através do método de "Complete Linkage" utilizando a distância Euclidiana, efetua um agrupamento hierárquico dos parâmetros morfométricos das bacias, identificando indivíduos mais parecidos entre si. Acreman \& Sinclair (1986) e Ferreira (1996) também utilizaram essa técnica de classificação multivariada para reconhecer bacias similares ou homogêneas.

Foram efetuados três tipos de análises com os parâmetros morfométricos, a saber: análise dos parâmetros totais $(O, F g, K f, L, A, P, F c l, S$, $D h T, D c T)$, análise dos parâmetros de encosta (AEnc, FcEnc, DhEnc, DcEnc) e análise dos parâmetros de planície costeira $(A P C, F C P C$, $D h P C, D c P C$ ), conforme exibido na Tabela 4.

Os dados apresentados na Tabela 4 revelam que ocorrem diversos agrupamentos de várias bacias que são bastante persistentes, e cujas associações se repetem pelo menos duas vezes nas três análises efetuadas, da seguinte forma:

a) grupos de Bacias de Alta Suscetibilidade: (B04, B05, B21, B25, B32); (B01, B02, B22, B24) e (B03, B06).

b) grupos de Bacias de Média Suscetibilidade: (B09, B11, B13, B15, B18, B19, B26, B28, B30) e (B07, B12, B20).

c) grupos de Bacias de Baixa Suscetibilidade: (B08, B17, B27, B29) e (B10, B14, B16, B23, B31).

Assim, por esses resultados, conclui-se

Tabela 4. Agrupamentos de bacias obtidos através do coeficiente de similaridade dos parâmetros morfométricos totais, de encosta e de planície costeira e comparação com os grupos de suscetibilidades obtidos

\begin{tabular}{|c|c|c|c|c|}
\hline $\begin{array}{l}\text { GRUPOS DE } \\
\text { BACIAS } \\
\text { SIMILARES }\end{array}$ & $\begin{array}{l}\text { PARÂMETROS } \\
\text { TOTAIS }\end{array}$ & $\begin{array}{l}\text { PARÂMETROS } \\
\text { DA ENCOSTA }\end{array}$ & $\begin{array}{l}\text { PARÂMETROS } \\
\text { DA PLANÍCIE } \\
\text { COSTEIRA }\end{array}$ & $\begin{array}{c}\text { GRUPOS DE BACIAS CONFORME A } \\
\text { SUSCETIBILIDADE } \\
\text { MORFOMÉTRICA }\end{array}$ \\
\hline GRUPO 1 & $\begin{array}{l}\text { B02, B03, B04, B06, } \\
\text { B07, B08, B10, B11, } \\
\text { B12, B13, B15, B18, } \\
\text { B23, B24, B25, B27, } \\
\text { B28, B30, B32 }\end{array}$ & $\begin{array}{c}\mathrm{B} 04, \mathrm{~B} 05, \mathrm{~B} 21, \mathrm{~B} 25, \\
\mathrm{~B} 32\end{array}$ & $\mathrm{~B} 04, \mathrm{~B} 05, \mathrm{~B} 25, \mathrm{~B} 32$ & \multirow{2}{*}{\begin{tabular}{|c|} 
Bacias de Alta Suscetibilidade: \\
B01, B02, B03, B04, B05, B06, B21, B22, \\
B24, B25, B32 \\
Bacias de Média Suscetibilidade: \\
B07, B09, B11, B12, B13, B15, B18, B19, \\
B20, B26, B28, B30
\end{tabular}} \\
\hline GRUPO 2 & B09, B14, B19, B31 & $\begin{array}{l}\mathrm{B} 08, \mathrm{~B} 09, \mathrm{~B} 11, \mathrm{~B} 13, \\
\mathrm{~B} 17, \mathrm{~B} 19, \mathrm{~B} 27, \mathrm{~B} 28, \\
\text { B29 }\end{array}$ & $\begin{array}{l}\text { B03, B08, B09, B11, } \\
\text { B13, B15, B17, B18, } \\
\text { B19, B26, B27, B28, } \\
\text { B29, B30 }\end{array}$ & \\
\hline GRUPO 3 & $\begin{array}{l}\text { B01, B16, B17, B20, } \\
\text { B22, B26, B29 }\end{array}$ & $\begin{array}{l}\mathrm{B} 02, \mathrm{~B} 07, \mathrm{~B} 10, \mathrm{~B} 12, \\
\mathrm{~B} 14, \mathrm{~B} 16, \mathrm{~B} 20, \mathrm{~B} 22, \\
\mathrm{~B} 23, \mathrm{~B} 24, \mathrm{~B} 31\end{array}$ & \begin{tabular}{|c|}
$\mathrm{B} 01, \mathrm{~B} 02, \mathrm{~B} 06, \mathrm{~B} 07$, \\
$\mathrm{B} 10, \mathrm{~B} 12, \mathrm{~B} 14, \mathrm{~B} 16$, \\
$\mathrm{B} 20, \mathrm{~B} 22, \mathrm{~B} 23, \mathrm{~B} 24, \mathrm{~B} 31$
\end{tabular} & \multirow{2}{*}{$\begin{array}{c}\text { Bacias de Baixa Suscetibilidade: } \\
\text { B08, B10, B14, B16, B17, B23, B27, B29, } \\
\text { B31 }\end{array}$} \\
\hline GRUPO 4 & B05, B21 & $\begin{array}{c}\text { B01, B03, B06, B15, } \\
\text { B18, B26, B30 }\end{array}$ & B21 & \\
\hline
\end{tabular}

que a classificação de Suscetibilidade Morfométrica obtida apresenta consistência estatística, sugerindo alto grau de confiabilidade para o método proposto.

\section{Considerações Finais}

Em geral, os valores dos parâmetros morfométricos apresentaram-se maiores nas bacias de Alta suscetibilidade e menores nas de Baixa. Relações diretamente proporcionais à classificação da suscetibilidade foram encontradas em função do tamanho (ordem, área, perímetro e comprimento do canal principal) das bacias, sendo que em geral as bacias de Alta suscetibilidade morfométrica são as maiores bacias, enquanto as de baixa suscetibilidade são as menores.

Dentre os parâmetros morfométricos analisados, 9 tipos parecem controlar mais as variações de suscetibilidade morfométrica nas bacias analisadas: densidade hidrográfica, densidade de confluências, declividade média do canal principal, freqüência de canais de $1^{\mathrm{a}}$ ordem, freqüência de canais totais e o tamanho das bacias 
(ordem, área, perímetro e comprimento do canal principal).

O método apresentado é bastante simples e econômico, podendo ser facilmente utilizado para qualquer número de parâmetros morfométricos. Além disso, um número ilimitado de bacias de qualquer região, com quaisquer características geológicas e hidrológicas, pode ser analisado conjuntamente, inclusive permitindo a identificação de bacias homogêneas sob o ponto de vista morfométrico e hidrológico.

A classificação da Suscetibilidade Morfométrica de bacias de drenagem ao desenvolvimento de inundações permite uma avaliação rápida e integrada sobre a atuação complexa de um conjunto de inúmeros fatores geométricos que se interrelacionam e controlam o comportamento hidrológico da bacia de drenagem. Ela constitui uma importante ferramenta na análise de risco a esses perigos hidrometeorológicos, principalmente em áreas onde dados hidrológicos não estão disponíveis.

A suscetibilidade morfométrica poderá ser utilizada como um dos atributos nos métodos de regionalização de bacias sujeitas a enchentes e inundações, bastante utilizado por hidrólogos para bacias onde não estão disponíveis dados hidrológicos.

\section{Agradecimentos}

Agradecimentos são devidos à matemática Vaudeluci M. da Silva, mestranda do curso de pósgraduação em Estatística do Instituto de Matemática e Estatística da USP, pela realização da análise dos coeficientes de similaridade.

Aos estagiários que trabalharam na obtenção dos dados morfométricos do Litoral Norte, Gustavo Leonardi Garcia (aluno do curso de Geografia do Departamento de Geografia da USP) e Thiago Forteza de Oliveira (aluno do curso de Engenharia Hídrica da Universidade Federal de Itajubá - UNIFEI/MG).

À FAPESP, pelo apoio financeiro do Projeto SIIGAL (Processo nº 98/14277-2).

\section{Referências Bibliográficacas}

Acreman, M.C. \& Sinclair, C.D. (1986) Classification of drainage basins according to their physical characteristics and application for flood frequency analysis in Scotland. Journal of Hydrology, 84: 365-380.

Baker, V.R. (1994) Geomorphological understanding of floods. Geomorphology, 10: 139-156.

Baker, V.R.; Kochel, R.C. \& Patton, P.C. (1988) Flood Geomorphology. J. Wiley \& Sons. 491 p.

Beven, K. \& Carling, P. (eds.) (1989) Floods: Hydrological, Sedimentological and Geomorphological Implications. John Wiley \& $\mathrm{S}$ o n s $\quad \mathrm{L} \mathrm{t} \mathrm{d.} \quad 289 \mathrm{p}$. Chorley, R.J. (1957) Climate and Morphometry.
Journal of Geology, 65: 628-639.

Chorley, R.J.; Malm, D.E.G. \& Pogorzelski, H.A. (1957) A new standard for estimating basin shape. American Journal of Science, v. 255, p. 138-141.

Christofoletti, A. (1969) Análise morfométrica das bacias hidrográficas. Notícia Geomorfológica, Campinas, 9(18): 35-64.

Cooke, R.U. \& Doornkamp J.C. (1990) Drainage Basins and Sediment Transfer. In: Geomorphology in Environmental Management. A New Introduction. Clarendon Press, $2^{\text {nd }}$ edition. 409p.

Ferreira, M.C. (1996) Regionalização de pequenas bacias hidrográficas a partir de imagens orbitais e sistemas de informação geográfica. Geociências, Rio Claro, 15(1): 163-184.

Horton, R.E. (1945) Erosional development of streams and their drainage basins: hydrophysical approach to quantitative morphology. Geological. Society America Bulletin, 56(3): 275-370.

ISDR (International Strategy For Disaster Reduction). (2002) Living with Risk. A Global Review of Disaster Reduction Initiatives. United Nations, Inter-Agency Secretariat. ISDR Secretariat. Preliminary Version. Geneva, Switzerland. 384p.

Lee, D.R. \& Salle, G.T.A. (1970) A method of measuring shape. Geographical Review, New York, 60(4): 555-563.

Morisawa, M.E. (1962) Quantitative Geomorphology of Some Watersheds in the Appalachian Plateau. Geological Society of America Bulletin, 73: 1025-1046.

Patton, P.C. (1988) Drainage Basin Morphometry and Floods. In: BAKER, V.R. et al. (eds.). Flood Geomorphology. John Wiley \& Sons. p. 51-64.

Patton, P.C. \& Baker, V.R. (1976) Morphometry and floods in small drainage basins subject to diverse hydrogeomorphic controls. Water Resources Research, 12(5): 941-952.

Sant'Anna Neto, J.L.; Souza, C.R de G. \& Tavares, R. (2003) Dinâmica climática, variabilidade pluvial e o risco à erosão costeira no Estado de São Paulo, Brasil. In: Congresso da Associação Brasileira de Estudos do Quaternário (ABEQUA), IX, Recife (PE), 12 19/outubro/2003. Anais, CD-ROM (trabalho completo).

Souza, C.R. de G. (1998) Flooding in the São Sebastião region, northern coast of São Paulo State, Brazil. Anais da Academia Brasileira de Ciências, Rio de Janeiro, 70(2): 354-366.

Souza, C.R. de G. (2003) Um sistema de informações geoambientais para o litoral de São Paulo. In: Congresso da Associação Brasileira de Estudos do Quaternário (ABEQUA), IX, Recife (PE), 12-19/outubro/2003. Anais, CD-ROM (trabalho completo).

Souza, C.R. de G.; Vedovello, R.; Brollo, M.J.; Tominaga, L.K.; Santoro, J. \& Holl, M.C. (2001) A cartografia geotécnica no sistema integrador 
de informações geoambientais para a zona costeira de São Paulo (Projeto SIIGAL). In: Simpósio Brasileiro de Cartografia Geotécnica, IV, Brasília (DF), 02-05/setembro/2001. ABGE. Anais (CD-ROM - trabalho completo).

Strahler, A.N. (1952) Hypsometric (area-altitude) analysis of erosional topography. Geological Society America Bulletin, 63: 1119-1142.

Strahler, A.N. (1964) Quantitative Geomorphology of Drainage Basins and Channel Network. In: CHOW, V.T. (ed.). Handbook of Applied Hydrology. McGraw-Hill. p. 4-40 4-74.

Tominaga, L.K.; Souza, C.R. de G.; Fereira, C.J.; Santoro, J. \& Vedovello, R. (2001) Avaliação de riscos geológicos para aplicação em instrumentos de gestão ambiental. In: Simpósio Brasileiro de Cartografia Geotécnica, IV, Brasília (DF), ABGE. Anais (CD-ROM trabalho completo).

Tucci, C.E.M. (Organizador) (1993) Hidrologia: ciência e aplicação. Editora da Universidade (RS), EDUSP e ABRH. 943 p.

Varnes, D.J. (1984) Landslide Hazard Zonation: Review of Principles and Practice. UNESCO Press, Paris. $56 \mathrm{p}$.

Zãvoianu, I. (1985) Morphometry of Drainage Basins. Developments in Water Science, v. 20. $2^{\text {nd }}$ Edition. Elsevier. 250 p. 